\title{
Legal safeguards and oversight innovations for bulk surveillance
}

\author{
An international comparative analysis
}

\author{
Thorsten Wetzling and Kilian Vieth
}

\section{Introduction}

All democratic countries rely on intelligence agencies to keep their open societies safe. These agencies provide actionable intelligence to decision-makers on a wide range of security and foreign policy matters. Regardless of whether this concerns terrorism, arms proliferation, or organized crime, information is required beyond that which is publicly available. Intelligence services master a range of clandestine methods to acquire such information. Some methodsincluding the electronic surveillance of communications data-are difficult to reconcile with the fundamental principles of democratic governance, such as the rule of law, transparency, and accountability. They may also infringe on fundamental human rights and civil liberties, such as the right to privacy as well as the rights to freedom of opinion, of expression, of association, and of assembly. In order to ensure public trust and the legitimacy of intelligence governance, democracies need to place all intelligence activities on a solid legal footing and subject them to rigorous and effective oversight.

The democratization of intelligence and the professionalization of oversight have made significant advances over the last few decades in many established democracies. Parliaments in Europe, North America, and Australasia, for example, have frequently reformed national intelligence laws and extended the remit and the resources of independent oversight bodies over time. In addition, countries such as the United States have introduced transparency principles that commit the intelligence community to providing more information to the public than at any previous time in history (Office of the Director of National Intelligence 2015). Still, as the failures of effective oversight of electronic surveillance prior to the revelations of Snowden have shown, democratic intelligence governance cannot be taken for granted. The stakes are high, and the temptations to abuse privileges such as government secrecy are omnipresent. Effective governance and democratic control of intelligence is the result of a complex, multifaceted effort that cannot be left to a small group of technocrats. Put simply, when democracies allow their intelligence services to deploy digital surveillance powers in the name of national security, 
they have to do this within the rubric of the rule of law and checks and balances. And while cultural, political, and constitutional differences across nations render it futile to establish a one-size-fits-all intelligence governance blueprint, it is certainly worthwhile to study how common challenges are met across different systems and to identify and promote innovative solutions so that they may traverse national jurisdictions.

In this chapter, we focus on the bulk surveillance of foreign communications. By this we mean the interception, collection, management, and transfer of enormous troves of communications data that is transmitted via different telecommunications networks (fixed telephone lines, mobile networks, the internet, and satellite networks). Foreign communications are intercepted as electronic signals, comprising various types of metadata as well as content. Bulk surveillance is controversial because it is "non-targeted" or "unselected" or "general" - in other words, not directed at a particular individual. David Anderson, the former UK Reviewer of Terrorism Legislation, warned that the use of bulk powers may have serious adverse human rights implications: such powers

involve potential access by the state to the data of large numbers of people whom there is not the slightest reason to suspect of threatening national security or engaging in serious crime [...] any abuse of those powers could thus have particularly wide ranging effects on the innocent [...] even the perception that abuse is possible, and that it could go undetected, can generate corrosive mistrust.

(Anderson 2016, 120)

Bulk surveillance of (foreign) communication has been a standard intelligence practice for decades. Greater public interest in the wake of the Snowden revelations, and the fact that many countries lacked a robust legal framework for it, let alone effective oversight thereof, have led many parliaments to adopt new laws or to amend existing legislation since then. Now that a sweep of new laws, oversight institutions, and control practices are in place it is time to take the national governance regimes at face value. While pending litigation at both national and European courts may still prompt a redesign of some intelligence laws, the very practice of bulk surveillance of communications is unlikely to be abandoned. Quite the contrary, it is here to stay and will remain a key practice of modern intelligence.

This makes it even more important to identify good solutions to the many thorny governance challenges entailed. This is what we aim to provide with our compendium, which we outline here. The full compendium, published by the Heinrich Böll Foundation and available online (Wetzling and Vieth 2018; Wetzling et al. 2020), identifies and contextualizes legal provisions and oversight practices from different democracies on bulk foreign communications surveillance that - by comparison — stand out for either their compatibility 
with democratic governance, the rule of law, or the protection of human rights. They are also seen as good practices when they embody an innovative attempt to improve the effectiveness of oversight.

We believe that all countries stand to benefit from a thorough discussion of the growing acquis of good practices regarding the governance and oversight of bulk surveillance of (foreign) communications. Despite the relevant and legitimate criticisms that can be directed at recent intelligence reforms (Lubin 2018), most of them also brought about individual changes that embody significant improvements in governance. When taken together, these promising practices paint a unique picture, which, in turn, can help identify opportunities for progress in national frameworks. Obviously, it takes knowledge to develop a reform agenda and political will to overcome national shortcomings. Yet, if other countries successfully demonstrate that the sky did not fall when they implemented more ambitious solutions to particular governance challenges, then this can be used as a powerful argument to persuade others to follow suit.

\section{Methods}

When democracies allow their intelligence services to conduct large-scale electronic surveillance of foreign communications data, they must do so within the limits of the law. They must also ensure that this practice is subject to effective and independent oversight. Yet, what does that mean in practice, and how can one best distinguish between good and poor legal safeguards and efficient and inefficient oversight dynamics?

To find out, we studied a wide range of different public resources, such as commentary on intelligence laws, oversight body reports, strategic litigation materials, as well as commentary on intelligence policy. We developed a scheme of analysis and conducted a series of interviews with a range of different experts (legal scholars, computer scientists, public servants and oversight professionals, industry representatives, etc.) to obtain further information on current practices (see the methodology section in Wetzling et al. 2020). Once we collected enough information, we wrote a draft compendium and organized two expert focus groups to further test and refine our findings. Based on this work, we produced a compendium of good practices on bulk surveillance of (foreign) communications from different national intelligence laws and oversight systems across Europe, North America, and Australasia, upon which this chapter is based.

Our focal points were the legal frameworks and oversight regimes regarding nontargeted signals intelligence (SIGINT), with a special emphasis on foreign communications data. This provides intelligence services "mass access [...] to data from a population not itself suspected of threat-related activity" (Forcese 2018, 3). Unsurprisingly, then, nontargeted (or "bulk") SIGINT capabilities are often considered to be the "crown jewels" of a national intelligence 
community. It is a technically sophisticated and highly complex intelligencegathering discipline that involves a lot of international cooperation and grew in the shadows of many democracies for quite some time.

What are the relevant aspects that one needs to consider when it comes to creating a legal basis for-and the democratic control of - bulk surveillance? According to what standards and criteria can we assess the quality of either a legal provision or an oversight practice? We consider a practice to be good when, by comparison, it provides an improved safeguard against potential violations of rights, or because it stands out in the way that it solves a common governance challenge, or because it may make innovative use of technology for the benefit of greater oversight effectiveness. Whether or not these standards are then observed in actual practice is another story. This needs to be independently and effectively reviewed based on the actual dynamics of judicial oversight as well as its resources, legal mandate, and technological tools.

\section{Building blocks of the good practice compendium}

This chapter devotes a section to each of the eight phases of bulk surveillance governance: (1) strategic planning, (2) application process, (3) authorization, (4) collection and filtering, (5) data processing, (6) analysis, (7) review and evaluation, and (8) reporting. For each phase we discuss good practice recommendations based on actual empirical examples adopted in particular countries; the full compendium available online includes references to specific examples of existing legal safeguards and concrete oversight practices from different systems up to the year 2019. ${ }^{1}$

\section{Phase I: strategic planning}

The first phase of the SIGINT process involves the identification and formulation of certain intelligence needs. Ideally, strategic planning will also draw on insights from previous assessments of collected intelligence and their value after analysis. A clear and specific legal mandate is the precondition for the transparency and accountability of foreign intelligence gathering. The mandate should describe specific legal grounds, against which the permissibility and proportionality of a particular measure can be assessed. It should also stipulate what data sources or types of communications may and may not be included in SIGINT collection.

According to jurisprudence by the European Court of Human Rights and the Court of Justice of the European Union, bulk surveillance is only permissible when it is strictly necessary to protect the democratic institutions of society (European Court of Human Rights 2015, 2016, 2018a, 2018b; Court of Justice of the European Union 2016). This indicates that intelligence services of signatory countries of the European Convention of Human Rights 
and the European Union Charter of Fundamental Rights may only engage in bulk collection techniques in relation to clearly confined categories of serious threats to a democratic society. These categories ought to go beyond a general understanding of what constitutes a serious threat.

The actors involved in setting intelligence priorities play a significant role here. There may be both external planning and tasking by government officials or ministers outside the service, and internal planning and tasking by the services. External planning and tasking traditionally focus more on a strategic/political level, whereas internal planning typically includes a stipulation of data sources or types of communications.

Good practices provide answers to questions such as: who can influence and challenge the tasking process? Does an evaluation of previous intelligence cycles feed into the planning of future intelligence collection? If so, how? When it comes to the formulation of concrete intelligence needs, does the process allow those with adversarial positions to challenge what may be taken for granted? Matters concerning cooperation with foreign intelligence agencies must also be addressed at this stage: will the need for cooperation with foreign services be weighed against other factors, such as human rights obligations and other national security interests? If so, how?

The compendium identifies four good practices from existing legal safeguards across a number of different countries. These include: laws ending discrimination based on citizenship; clear rules for setting intelligence priorities; regulating international cooperation; and prohibition of objectives that may not be advanced through bulk collection. ${ }^{2}$

Setting strategic goals and formulating operational priorities is a core competence of the executive. Consequently, we found only very limited involvement of oversight bodies in the tasking and planning phases. Privacy International also found recently that no intelligence oversight body currently possesses the power to authorize decisions to share intelligence (Privacy International 2018). Clearly, this invokes not just legal and operational questions but also political ones. Can a government sufficiently trust a foreign service to engage in new cooperations? Nonetheless, some oversight bodies have recently taken an interest in reviewing the tasking of and cooperation between intelligence services.

\section{Phase 2: application process ("warrantry")}

With a warrant, the intelligence service (or, as the case may be, the ministry performing executive control over a particular intelligence service) submits an application for authorization to collect data in bulk. Warrants need to describe and delimit bulk SIGINT measures based on specific criteria regarding both the form and content of the warrant that are set out in law. Warrants are a core element of accountability in intelligence governance, although they have to provide detail and particularity in order to constitute an effective safeguard against overly intrusive surveillance authorities. ${ }^{3}$ 
In the SIGINT world, warrants might therefore be tied to classes of individuals or activities rather than specific persons. Some jurisdictions apply much stricter limits to the legal concept of a warrant. In the United States and Canada, for instance, warrants always refer to targeted surveillance operations that involve a judge, who has to authorize them. A range of countries in Europe only apply the concept of warrants to criminal investigations and not to intelligence collection. In this conventional understanding, "bulk powers are irreconcilable with the requirements of classic warrants. There is no specificity. By definition, bulk powers are not targeted; they are indiscriminate" (Forcese 2018, 3). Under the United Kingdom's Investigatory Powers Act, on the other hand, the term "warrant" is used for different types of applications for bulk interception or acquisition of data. This, then, implies a class-based warranty system, in which large categories of data can be collected.

Although the terminology is tricky and warrants for untargeted collection or bulk surveillance are not a feature of some legal systems, they are included here as a useful comparative category. Warrants can be a powerful tool to specify the minimization rules, the authorization requirements, and the purpose limitations of a measure. The more specificity a bulk warrant can provide, the better its protective function. Warrants may also be used to exclude certain data categories from collection and limit the use of the data collected. It is important to note that many such limits and conditions could appear in a law governing intelligence surveillance. The major advantage of warrants, though, is the active involvement of an independent judicial authorization body before the collection begins (see phase 3 ), which allows for case-by-case controls. Ideally, a clear legal mandate is combined with obligatory, independent, ex ante controls of all applications for bulk data collection.

Warrants also often define the duration of an operation for a specific collection method. This, in turn, triggers a mandatory reassessment of the measure, and potentially the subsequent reapplication and reauthorization. Setting an expiration date is, hence, an accountability mechanism as well as a regular efficacy test that helps to ensure the efficient allocation of resources by the agencies.

Naturally, the more targeted an envisaged surveillance operation, the more specific the warrant can be formulated. Given the focus of this chapter, that is, safeguards and oversight innovation regarding nontargeted communications surveillance, we mostly reviewed types of "bulk" warrants. That said, interesting features in targeted surveillance warrants might be discussed when applicable to the sphere of untargeted collection.

It is common for various intelligence laws to include a list of criteria that each application for a SIGINT measure needs to address. Ideally, these include:

- Purpose(s) of the requested activity;

- $\quad$ Alternative means available; 
- Private companies that may be compelled to cooperate;

- Service or services that will be instructed to perform the activity;

- Time frame for assessment and authorization of the warrant, including for emergency situations;

- Geographical zones or organizations or groups of people that a particular measure is directed at;

- Technical device or facility to be tapped;

- Exploratory monitoring or preliminary aptitude tests that have been conducted in preparation;

- Type(s) of data to be retrieved;

- Search terms or selectors used (i.e., a range of IP addresses);

- Types of data use and forms of data exploitation to be performed on the data;

- Duration of the warrant and rules for renewal; and

- Additional background materials to be submitted with the warrant.

The various forms of bulk warrants that now exist in many countries highlight the potential for even broader applications of this accountability mechanism in the field of foreign communications surveillance. There is a need to think more creatively about further relevant criteria and additional aspects that add more precision to bulk warrants. For example, lawmakers could ask the executive to specify the actual use of minimization procedures and how the intelligence services intend to honor data-use limitations.

\section{Phase 3: authorization/approval}

After a warrant has been issued, the requested bulk SIGINT measure must be authorized or - as the case may be in different jurisdictions - approved by a review body that assesses the necessity and proportionality. Differences exist across nations as regards the moment when the independent judicial review process comes into play. In some countries, the competent minister or other members of the executive authorize warrants. In the United Kingdom, for example, the authorization of warrants is the privilege of the executive. Ministerial authorization, then, has to be approved by independent Judicial Commissioners. By contrast, in the German legal framework, warrants are authorized by bodies such as the G10 Commission or the Independent Committee.

The independent ex ante authorization/approval of data collection is a crucial safeguard against the misuse and abuse of bulk surveillance powers. The legitimacy of surveillance practice depends on the control of executive conduct from the outside. Enacting the control mechanism prior to implementation is crucial, because this can both deter and prevent certain actions from being taken. Independent authorization/approval also contains an important learning element, because the competent bodies can improve their controls, 
draw lessons from past mistakes, and then declare more assertively that certain measures are not required, or that no sufficient proof was presented.

Across many democracies, a dual system of authorization/approval has emerged that combines a judicial and an executive control function. A judicial oversight body — ideally a court — is best suited to administer a competent legal review of a bulk surveillance application. But, as several discussions with intelligence oversight practitioners have shown, the involvement of the political leadership level, for example, the responsible minister or secretary of state, may also present a relevant safeguard, especially in the realm of foreign intelligence. The acceptance of a surveillance operation may go beyond legal criteria of necessity and proportionality and move into the political domain. Including political considerations, such as possible damage to diplomatic relations with a foreign country, may add an important perspective to the authorization process.

The complexity and confidentiality of the subject matter require that the authorization body be sufficiently qualified (e.g., a specialized court for SIGINT operations) and have the necessary powers and resources to conduct the authorization (e.g., access to all relevant information) (European Court of Human Rights 2015, 275). A fundamental requirement for an authorization/approval body is its independence. Further relevant aspects include:

- Who is involved in the authorization process?

- How is the independence of the authorization/approval ensured? For example, unified, fully resourced authorization bodies with full access rights are far better equipped to conduct comprehensive reviews.

- When does the review take place? Prior to, or after the implementation of bulk surveillance measures?

- How does the authorization take place?

- Are all warrants independently authorized, or does the law account for exceptions? For example, are there any exceptions for emergency procedures? If so, are they designed so that they do not unduly open up loopholes for unauthorized operations?

- What assessment criteria are being used?

- How explicit are the oversight bodies as regards the use of criteria to assess the legality, necessity, and proportionality in concrete practice?

- How much time does the oversight body have to assess a warrant?

- Does the law foresee an appeal procedure?

- Are the authorization decisions legally binding?

- Is technical and adversarial advice incorporated into the authorization process? If so, how?

- Do the warrants also account for metadata and "secondary data" (Smith 2018)?

- Does the authorization take other (ongoing) surveillance measures into account when assessing a new warrant? 
- How is the authorization decision documented? Are there publicly available statistics on the number of rejections and the total number of applications reviewed?

Current good practices in existing legal safeguards include laws that provide a margin of discretion for authorization bodies; mandatory public reporting on individual authorization decisions; adversarial proceedings that provide additional input legitimacy to the authorization/approval decision process; quotas for maximum permissible number of certain surveillance instruments. Good oversight practices include explicit standards for proportionality assessments when approving bulk SIGINT warrants in actual practice. For a detailed discussion of the relevant legislation supporting these practices, see the full compendium (Wetzling and Vieth 2018; Wetzling et al. 2020).

\section{Phase 4: collection and filtering}

Once a warrant has been authorized or approved, an intelligence agency can proceed with the implementation of a particular surveillance measure. For this, it intercepts the relevant signals, for example, by tapping an internet service provider's (ISP) fiber optic backbone cable or diverting data at an internet exchange point. Afterward, the collected data has to be filtered for two reasons: first, because of the huge volumes passing through-which would be far too much to be stored long term-gratuitous data that is extremely unlikely to yield any intelligence value is filtered out (e.g., all data from public video feeds); second, the collected data stream has to be filtered so as to abide by legal requirements. Certain data - for example, domestic communications or communications involving lawyers, priests, or other professions relying on the confidentiality of correspondence - may be offered higher levels of protection in national surveillance laws. ${ }^{4}$

\section{Collection}

At the collection point, it is critical to clearly define who is in charge of extracting the data and where and how the extraction devices may be installed. Is the collection administered by the intelligence service, or do private entities (e.g., ISPs) do this on behalf of the intelligence services? This distinction is relevant, as provider intermediation can be an important safeguard against overcollection. In principle, intelligence agencies should not have direct access to the facilities of telecommunications providers. Cases have surfaced, however, in which internet companies agreed to search the data they administer on behalf of an agency. Yahoo, for example, secretly scanned all email accounts for information provided by US intelligence agencies (Menn 2016). A legal framework, therefore, has to define how (private) intermediaries may be compelled to cooperate and what means are available for operators to challenge particular measures. 
A number of European countries have installed electronic interfaces that give oversight bodies direct access to operational systems and collected data. Such direct access can be an important innovation for oversight, but it also entails risks that have to be addressed. The advantage of direct access to databases is that the oversight body can conduct random checks, unannounced inspections, and potentially also automated controls on the data handling by the intelligence agencies. This has the potential to level the playing field between the controller and the controlled. Traditionally, oversight bodies depend, to a large extent, on the information provided by the intelligence services. If overseers gain direct access, the incentive to comply increases because intelligence officials cannot know whether an incident will be reviewed or not. Technical interfaces might also empower review bodies to monitor statistical anomalies in the databases. This opens a new field of (automated) oversight applications that will support overseers in effectively diverting their limited resources for in-depth compliance auditing. Such an approach-using analytical techniques to identify potential noncompliance-amounts to "predictive oversight" and is already being practiced by institutions entrusted with financial audits in the banking sector. ${ }^{5}$

Granting direct, unfettered access for oversight bodies to the intelligence databases may, however, turn them into attractive targets for foreign espionage and hacking attacks. It is important, therefore, to only grant such access to properly trained oversight personnel and to provide the highest level of cybersecurity to oversight bodies.

Making sense of raw intelligence data and log files is hard. It is not enough for oversight bodies to merely have access. The information advantage that direct access may bring comes from data analytics. In other words, oversight bodies need to engage with the data that they now have access to. In order to learn how much more rigorous their controlling could become, overseers may want to learn from financial audit bodies and will need special training.

\section{Filtering}

Once data has been acquired by means of untargeted electronic surveillance, it may be subject to additional filtering, depending on the national surveillance regulations. The specifics of the data minimization and filtering processes should be subject to critical review, for they may reveal the extent to which intelligence agencies abide by constitutional and human rights standards. For example, some intelligence laws grant enhanced privacy protection to professions that depend on the confidentiality of information. This may pertain to communications involving priests, lawyers, journalists, and physicians. Whether and how data minimization and filter tools are capable of accommodating such communications in practice should be of interest to oversight bodies. This may also extend to the review of protected health data and DNA-related information. 
In addition, there are technical questions that come to mind, as they, too, reveal interesting information about the independence of oversight bodies and the extent to which data minimization is an actual priority (or not) within the intelligence community. For instance, how is "surplus information" treated in the collection and filtering process? When data minimization systems, such as the Massive Volume Reduction (MVR) systems of the United Kingdom's Government Communications Headquarters (GCHQ), are being used, are they subject to independent oversight? More specifically, are the technical equipment and filter programs regularly subject to independent verification, or do the oversight bodies merely rely on the assurances of the intelligence agencies that the data minimization and filtering processes are fit for purpose?

The independent verification of data minimization techniques deserves greater attention from oversight bodies (Vieth and Wetzling 2019, 18ff). They ought to investigate the technical implementation of the filtering process and the independent auditing of filter effectiveness. Similarly, the deletion of data is an ongoing oversight challenge that many review bodies are gradually waking up to. Here, we find that mutual learning from regular exchanges with other oversight bodies in other countries and the promotion of systematic dialogues with external experts should be intensified.

\section{Phase 5: data processing}

Once data has been collected and filtered, it must be stored, tagged, and later removed or destroyed. This phase of the SIGINT process is particularly relevant for oversight and the services because lawful and efficient data management is the basis for relevant data analysis. For the sake of clarity, this phase is divided into four subcategories reflecting the different facets of data processing: storage, maintenance, sharing, and deletion.

\section{Data storage}

Due to different retention periods, it may become necessary to keep separate databases, for example, for encrypted data, metadata, and content data, or in order to distinguish data pools according to their legal basis or warranted purposes. It can therefore be relevant whether there are isolated data storage locations. Increasingly, bulk surveillance governance relies on the verifiable technical or institutional separation between the authority to intercept and the authority to analyze the data. In order to honor data protection obligations, a surveillance law should further restrict the extent to which databases may be linked or accumulated.

Transnational threats prompt closer transborder cooperation among intelligence services, not least for neighboring countries. Intelligence data - both unevaluated and evaluated - is therefore not just shared bilaterally but also stored in joint intelligence databases for different threats and purposes. 
When we speak of joint databases, we refer to a multilateral exchange of data that can be hosted either on national territory or abroad. Typically, joint databases are run multilaterally, with all participating services adding and accessing data.

The European Counter Terrorism Group (CTG), for example, runs a database that facilitates the multilateral exchange of evaluated data on individuals who have traveled to and returned from certain conflict areas (CTIVD 2018, 10; see also van Eijk and Ryngaert 2017). This database became operational in July 2016, is administered on servers in the Netherlands, and makes information available in (near-) real time to the 30 participating services of the CTG. Interestingly, unevaluated data may also be exchanged within the CTG, although not via the database. It may be jointly stored and processed within standard SIGINT cooperations (CTIVD 2018, 9).

Existing good practices in legal safeguards include laws that protect all data categories and, in particular, that allow for no distinction between rules regulating metadata and content data retention since both are worthy of protection; explicit obligations regarding joint databases with foreign intelligence services, including obligations to keep a file classification scheme, appropriations clauses for joint databases, and equalized retention rules for citizens and noncitizens. ${ }^{6}$

\section{Data maintenance}

This comprises all practices that concern the labeling and registration of intelligence databases. Data upkeep is not only required by data protection regulations but also serves a practical end: it ensures that the services keep only relevant and accurate data.

Relevant aspects for good practices include: how is bulk data tagged? And what authority do data protection agencies have to investigate the sound implementation of databases? For auditing purposes, data must be traceable throughout the entire lifecycle. It is also important to anonymize data to the greatest extent possible. The security and quality of the databases must be ensured to protect sensitive information from being stolen or compromised. Adequate data maintenance also builds on clear restrictions of data access. Is the access to the stored data regulated by law and restricted to specialized personnel only? Or is data access for operational teams limited by data exploitation warrants (see phase 2)?

Existing good practices in legal safeguards include legally imposed duty of care with regard to data processing, including the use of algorithms, avoiding data breaches, and insuring the validity and integrity of processed data; the mandatory tagging of all bulk SIGINT data as a precondition for meaningful data protection controls. In terms of oversight, good practices include the obligation to perform regular reviews of intelligence registration and data processing. 


\section{Data sharing}

Sharing data with foreign services entails a responsibility to assess and mitigate the risk of misuse of the shared data. Although SIGINT burden-sharing among partner services is a common practice, what rules and procedures are in place to evaluate partner services' data quality and data veracity? Oversight of - and accountability for-data-sharing agreements and joint databases must be ensured. Finally, in times of advanced joint intelligence databases, how do oversight bodies cooperate internationally to control the permissible use of international data pools? Current good practices include rules for oversight body access to shared data and random sample checks on automatic transfers of personal data to foreign intelligence services.

\section{Data deletion}

The proper deletion of data is an enormous challenge. Technically, it is not as easy as one may think to securely "get rid" of data. This is because "deleting" a file typically only marks the space it occupies as usable. Until the disk space is overwritten, the data is still there and can be retrieved. To ensure that the deleted data cannot be retrieved any longer, the physical records on a storage medium must be overwritten with other data several times (minimum of seven times as per the US Federal government's guidelines) (Dorion 2008). But simply overwriting the storage space on a physical medium with new data does not necessarily guarantee that none of the old data is gone for good. Although there are technical means to ensure that deleted data is actually unretrievable, it seems necessary to develop more detailed standards for what constitutes the proper deletion of data. Errors in this process could result in millions of datasets being falsely stored for years.

Moreover, it is now also "more costly to delete data, than retain it" (OECD 2013, 100). Therefore, legislators have found it difficult to insert the proper legal definitions or public standards for what "deletion" or "destruction" of data means into intelligence laws. ${ }^{7}$ By extension, then, the deletion problem also becomes a veritable oversight challenge. This is because review bodies need accurate audit trails to be able to check services' compliance with data deletion requirements. This may include the automated destruction of data after legal retention periods have lapsed or if the relevant authorization for collecting data has ended.

There is also a need for better guidelines on what data should be deleted at what point in time. Storage periods (see part one of phase 5 above), for that matter, define maximum times for which data may be retained. With adequate normative criteria at hand, the services or the competent oversight bodies could, theoretically, also decide to apply a shorter storage period. For example, if a system flags data that has not been used for a certain time period, this should then prompt a check as to whether this specific dataset is still needed. 
Intelligence law should outline specific and short retention periods, after which the data must be permanently and unmistakably destroyed. There might be special requirements for the deletion of large amounts of data. For example, the NSA's XKeyscore system may have a rolling buffer so that new incoming data automatically overwrites the old data. It is also relevant how data destruction is documented and controlled by the competent oversight body. For example, is stored data linked to specific warrants, and does it have traceable time stamps for full and proper deletion? Adequate records of the data destruction are also important for possible notification purposes.

Relevant aspects for good practices include: how are storage and deletion implemented in practice? Should intelligence data be stored in "clouds"? Even in the sphere of national security, we witness close cooperation with commercial third parties, such as private cloud storage services (Konkel 2014). How can it be ensured that such outsourcing - entailing the risk of shifting responsibility for a crucial phase of data processing to private companies - does not undermine democratic accountability and oversight?

Existing legal safeguards include legal obligations to immediately delete data tied to rejected applications; obligations to destroy data from bulk collection that is deemed irrelevant; and obligations to delete health data in foreign datasets. Good existing oversight practices include running statistical pattern analysis on the amount of deleted material and independent review of compliance with deletion obligations.

\section{Phase 6: analysis}

A wide range of data use is relevant for this phase. There are, of course, overlaps between data processing and data analysis. Whereas data processing refers to data registration and other formal or technical data management practices, in this phase data becomes information that is relevant for political decision-making. Different automated data analysis methods serve different purposes and are governed by their own specific rules. Bulk datasets are used both to "establish links between known subjects of interest" as well as to "search for traces of activity by individuals who may not yet be known but who surface in the course of an investigation, or to identify patterns of activity that might indicate a threat" (UK Home Office 2017, 52). For example, contact chaining is one common method used for target discovery:

Starting from a seed selector (perhaps obtained from HUMINT), by looking at the people whom the seed communicates with, and the people they in turn communicate with (the 2-out neighbourhood from the seed), the analyst begins a painstaking process of assembling information about a terrorist cell or network.

(GCHQ 2011, 12) 
Automated pattern analysis and anomaly detection increasingly rely on artificial intelligence (AI) methods such as machine learning and predictive analytics. "AI is expected to be particularly useful in intelligence due to the large datasets available for analysis" (Hoadley and Lucas 2018, 13). The risks and benefits generally associated with AI also challenge existing oversight methods and push legislators as well as oversight practitioners to creatively engage with AI as a dual-use technology. In intelligence, AI "is intended to automate the work of human analysts who currently spend hours sifting through data for actionable information. It may free them to make more efficient and timely decisions based on the data" (Hoadley and Lucas 2018, 9). Conversely, malicious use of AI creates new security threats that have to be mitigated (Brundage et al. 2018).

Good practices need to consider the following questions: what types of data use are permissible in a given legal framework, and are there specific rules for different forms of data use? For example, there should be procedures for each type of use, specifying the circumstances under which that specific use is permitted. There should also be independent oversight (internal and external) over bulk data analysis techniques, including rules and safeguards as concerns the use of AI. How is the level of privacy intrusion of specific data-analysis tools measured? And what kind of material is fed into queryfocused databases? How is the convergence of different databases/data sources regulated? For example, may bulk communications data be matched with other stored data (such as data gathered via sensors or in hacking operations) or publicly available data? If so, does such enrichment of material happen automatically?

Current good legal safeguards include human-in-the-loop safeguards for automated data analysis that prohibit action on the basis of automated results alone, as well as legally required specialized training for analysts. Good oversight practices include automated internal compliance systems for data analysis and ex ante review of AI experiments and novel data analysis techniques.

\section{Phase 7: review and evaluation}

Compliance with legal safeguards must be ensured through comprehensive and regular judicial oversight. Examining the effectiveness of data collection measures is equally important. Overseers need to know about this to assess the political value, the cost efficiency, and the need for the reauthorization of warrants. Identifying suitable metrics and methods for this remains a considerable challenge. For example, if data from a certain program or collection stream never feeds into the production of intelligence reports, does this mean that the particular data collection is superfluous and a strain on the limited resources of the intelligence community? Or, in contrast, would this be tantamount to someone canceling a fire insurance policy simply because, thus far, their house has not caught fire? 
The scope of the review mandate of the oversight body is a core factor. Effective review presupposes that there are no gaps in the control mandate. Control remits should be defined functionally, covering all aspects of intelligence collection, as recommended by the Council of Europe (Council of Europe 2015). Does the competent oversight body have the sufficient resources (staff, time, money, technical expertise) to conduct meaningful reviews? Intelligence law should also define the role for oversight in assessing the political relevance of finished intelligence operations and assign the duty to the executive branch to demonstrate the efficiency of its bulk surveillance measures, despite the ubiquitous presence of open-source information.

Existing good legal safeguards include laws that expand the scope of oversight and put in place a holistic review of SIGINT practices across different agencies; mandatory reauthorization of legislation and verification of effectiveness before renewal of authorization; and criminal liability for noncompliance with oversight requests. Good oversight practices include early and systematic oversight involvement; obligatory quarterly self-reporting of incidents to the Inspector General; and international cooperation of oversight bodies, including joint review and mutual learning sessions.

\section{Phase 8: reporting}

After a SIGINT collection cycle has been completed, both government and oversight bodies need to be transparent and provide adequate information about both the surveillance activities undertaken by the state and their specific oversight activities thereon. To enhance public trust, the intelligence services should proactively declassify key legal documents of public interest. ${ }^{8}$ Such releases have, for example, allowed the creation of rare public and quite comprehensive accounts of different types and patterns of compliance violations over the duration of the Section 702 program. ${ }^{9}$ Although full transparency of oversight activities may not be possible due to secrecy requirements, the regular reporting by oversight bodies is a crucial means for public trust and accountability. For this, it ought to be as comprehensive and timely as possible.

Relevant considerations include: what rules are in place regarding mandatory, periodical public reporting on surveillance measures and their democratic control? Information on oversight methods and capacities, especially with a view to bulk surveillance, should be provided to the greatest extent possible. Reports should draw a holistic picture of all intelligence activities. What contextual material and statistical information is provided to the public? What outreach activities are pursued, and how does the oversight body communicate with the public?

Existing good practices in legal safeguards include allowances for deviations from the norm of classification and options for declassification, and legal obligations to inform about errors. Good practices in oversight include 
reporting on nonconformities with selectors; oversight bodies pushing for declassification; and institutional support and protection for whistleblowers.

\section{Conclusion}

Our initial review of legal safeguards and oversight innovations in different stages of the bulk surveillance governance process features 64 good practices. These range from ending discrimination based on citizenship to more specific authorization regimes and additional safeguards for international intelligence cooperation. Each pertains to different aspects of surveillance governance. More specifically, this includes:

- Restriction of bulk surveillance powers;

- Transparency;

- Access;

- Oversight professionalism;

- International cooperation;

- Direct government responsibility;

- Sanctions; and

- Private-sector involvement.

Reforms of bulk surveillance post-Snowden have been limited and underwhelming in the eyes of many observers. Yet, the debate about rightsbased and democratically controlled surveillance governance is far from over. Although courts such as the European Court of Human Rights tend to grant a broad leeway to national governments to implement bulk surveillance, they also insist on adequate safeguards. What this means in practice, however, will not be decided by the courts. Rather, it involves the hard work of taking the lessons about ineffective oversight and applying better practices through the slow and steady channels of democratic institutions. In this spirit, we continue to collect and compare international good legal safeguards and promising oversight practices (Wetzling et al. 2020). This may not be the Snowden legacy that some expected. Yet, it is the difficult and necessary work of democratic governance.

\section{Notes}

1 An up-to-date collection of international good practices is available at: www. intelligence-oversight.org.

2 References to empirical examples in phase 1 can be found here: www.intelligenceoversight.org/phases/strategic-planning/.

3 Laura Donohue interviewed by Henry Farrell in Farrell (2016).

4 As established earlier, it is not always technically possible to filter out the communications of protected categories such as certain professions. 
5 For a detailed analysis of potential applications for direct oversight access to operational surveillance systems, see Vieth and Wetzling (2019).

6 References to the individual good practices in the data processing phase are available at: www.intelligence-oversight.org/phases/data-processing/.

7 We are grateful to Professor Nico van Eijk, who presented valuable information on the legal and technical challenges of data deletion during our workshop on May 14, 2018.

8 The US intelligence community, for example, has released official documentation of intelligence activities and procedures, such as declassified FISC opinions, quarterly reports, and semiannual assessments. Many of these documents can be found at www.icontherecord.tumblr.com. A guide to released documents is available here: www.dni.gov/files/CLPT/documents/Guide_to_Posted_Documents. pdf. A searchable database of all documents is available at: www.intel.gov/ ic-on-the-record-database.

9 Robyn Greene has compiled highly informative documentation that informs the public about how unintentional violations may threaten the privacy of protected communications over a longer period of time "with significant and prolonged impact" (Greene 2017). For a summary of compliance reports under Section 702 of FISA, see Greene (2017).

\section{References}

Anderson, David. 2016. "Report of the Bulk Powers Review.” London: Independent Reviewer, https://terrorismlegislationreviewer.independent.gov.uk/wp-content/ uploads/2016/08/Bulk-Powers-Review-final-report.pdf.

Brundage, Miles, Shahar Avin, Jack Clark, Helen Toner, Peter Eckersley, Ben Garfinkel, Allan Dafoe, et al. 2018. "The Malicious Use of Artificial Intelligence: Forecasting, Prevention and Migration." February 2018, https://arxiv.org/ftp/arxiv/papers/1802/ 1802.07228.pdf.

Council of Europe. 2015. "Democratic and Effective Oversight of National Security Services." Strasbourg, https://rm.coe.int/democratic-and-effective-oversight-ofnational-security-services-issue/16806daadb.

Court of Justice of the European Union. 2016. "C-203/15 Tele2 Sverige AB v PostOch Telestyrelsen and C-698/15 SSHD v Tom Watson \& Others." December 2016, http://curia.europa.eu/juris/document/document_print.jsf?doclang $=\mathrm{EN} \&$ text $=\& p$ ageIndex $=0 \&$ part $=1 \&$ mode $=1$ st $\&$ docid $=186492 \&$ occ $=$ first $\&$ dir $=\&$ cid $=406338$.

CTIVD-Commissie van Toezicht op de Inlichtingen-en Veiligheidsdiensten. 2018. "Review Report: The Multilateral Exchange of Data on (Alleged) Jihadists by the AIVD." CTIVD No. 56, https://english.ctivd.nl/documents/review-reports/2018/04/ 24/index.

Dorion,Pierre.2008. “Data DeletionorDataDestruction?”SearchDataBackup.July2008, https://searchdatabackup.techtarget.com/tip/Data-deletion-or-data-destruction.

Eijk, Nico van, and Cedric Ryngaert. 2017. "Expert Opinion-Legal Basis for Multilateral Exchange of Information," Appendix IV of CTIVD Rapport No. 56 to the Review Report on the Multilateral Exchange of Data on (Alleged) Jihadists by the AIVD, https://pure.uva.nl/ws/files/36129088/Expert_opinion_CTIVD.pdf 
European Court of Human Rights. 2015. "Case of Roman Zakharov v. Russia (Application No. 47143/06)." Strasbourg, http://hudoc.echr.coe.int/eng?i=001159324.

European Court of Human Rights. 2016. "Case of Szabó and Vissy v. Hungary (Application No. 37138/14)." Strasbourg, http://hudoc.echr.coe.int/eng?i=001160020.

European Court of Human Rights. 2018a. "Case of Paul Popescu v. Romania (Application No.64162/10).”Strasbourg, http://hudoc.echr.coe.int/eng?i=001-80353.

European Court of Human Rights. 2018b. "Case of Centrum För Rättvisa v. Sweden (Application No. 35252/08)." Strasbourg, http://hudoc.echr.coe.int/ eng?i=001-183863.

Farrell, Henry. 2016. "America's Founders Hated General Warrants. So Why Has the Government Resurrected Them?" Washington Post, June 14, 2016, www. washingtonpost.com/news/monkey-cage/wp/2016/06/14/americas-founders-hatedgeneral-warrants-so-why-has-the-government-resurrected-them/.

Forcese, Craig. 2018. "Bill C-59 and the Judicialization of Intelligence Collection. Draft Working Paper 04-06-18." Ottawa Faculty of Law Working Paper No. 2018-13.

GCHQ-Government Communications Headquarters. 2011. "HIMR Data Mining Research Problem Book." September 20, 2011, www.documentcloud.org/ documents/2702948-Problem-Book-Redacted.html.

Greene, Robyn. 2017. "A History of FISA Section 702 Compliance Violations." New America. September 28, 2017, www.newamerica.org/oti/blog/history-fisa-section702-compliance-violations/.

Hoadley, Daniel S., and Nathan J. Lucas. 2018. "Artificial Intelligence and National Security." Congressional Research Service. April 26, 2018, https://fas.org/sgp/crs/ natsec/R45178.pdf.

Konkel, Frank. 2014. "The Details About the CIA's Deal with Amazon.” The Atlantic, July 17, 2014, www.theatlantic.com/technology/archive/2014/07/the-details-aboutthe-cias-deal-with-amazon/374632/.

Lubin, Asaf. 2018. "Legitimizing Foreign Mass Surveillance in the European Court of Human Rights." Just Security, August 2, 2018, www.justsecurity.org/59923/ legitimizing-foreign-mass-surveillance-european-court-human-rights/.

Menn, Joseph. 2016. "Exclusive: Yahoo Secretly Scanned Customer Emails for U.S. Intelligence Sources." October 5, 2016, www.reuters.com/article/us-yahoo-nsaexclusive/yahoo-secretly-scanned-customer-emails-for-u-s-intelligence-sourcesidUSKCN1241YT.

OECD-Organisation for Economic Co-Operation and Development. 2013. "The OECD Privacy Framework," www.oecd.org/sti/ieconomy/oecd_privacy_framework.pdf.

Office of the Director of National Intelligence. 2015. "US Principles of Intelligence Transparency for the Intelligence Community," www.dni.gov/index.php/ic-legalreference-book/the-principles-of-intelligence-transparency-for-the-ic.

Privacy International. 2018. "Secret Global Surveillance Networks: Intelligence Sharing Between Governments and the Need for Safeguards," http://privacyinternational. org/feature/1742/new-privacy-international-report-reveals-dangerouslack-oversight-secret-global. 
Smith, Graham. 2018. "Illuminating the Investigatory Powers Act." Cyberleagle, February 22, 2018, www.cyberleagle.com/2018/02/illuminating-investigatorypowers-act.html.

UK Home Office. 2017. "Interception of Communications. Pursuant to Schedule 7 to the Investigatory Powers Act 2016. Draft Code of Practice.” December 2017, https://assets.publishing.service.gov.uk/government/uploads/system/uploads/ attachment_data/file/593748/IP_Act_-_Draft_Interception_code_of_practice_ Feb2017_FINAL_WEB.pdf.

Vieth, Kilian, and Thorsten Wetzling. 2019. "Data-Driven Intelligence Oversight: Recommendations for a System Update." November 2019, https:// guardint.org/2019/11/28/data-driven-intelligence-oversight-recommendations-fora-system-update/.

Wetzling, Thorsten, and Kilian Vieth. 2018. "Upping the Ante on Bulk Surveillance: An International Compendium of Good Legal Safeguards and Oversight Innovations." Heinrich Böll Stiftung, www.stiftung-nv.de/en/publication/upping-ante-bulksurveillance-international-compendium-good-legal-safeguards-and.

Wetzling, Thorsten, Kilian Vieth, and Charlotte Dietrich. 2020. "Intelligence in Democracies: International Repository of Legal Safeguards and Oversight Innovation," www.intelligence-oversight.org. 